\title{
BMJ Open Vitamin D status in tuberculosis patients with diabetes, prediabetes and normal blood glucose in China: a cross- sectional study
}

\author{
Xin Zhao, ${ }^{1}$ Yanli Yuan, ${ }^{2}$ Yan Lin, ${ }^{3,4}$ Tiejuan Zhang, ${ }^{2}$ Jianjun Ma, ${ }^{2}$ Wanli Kang,,${ }^{5,6}$ \\ Yunlong Bai, ${ }^{2}$ Yunlong Wang, ${ }^{7}$ Hongshan Shao, ${ }^{8}$ Riitta A Dlodlo, ${ }^{3,9}$ \\ Anthony D Harries ${ }^{3,10}$
}

To cite: Zhao $X$, Yuan $Y$, Lin $Y$, et al. Vitamin $D$ status in tuberculosis patients with diabetes, prediabetes and normal blood glucose in China: a cross-sectional study. BMJ Open 2017;7:e017557. doi:10.1136/ bmjopen-2017-017557

- Prepublication history for this paper is available online. To view these files please visit the journal online (http://dx.doi org/10.1136/bmjopen-2017017557).

Received 4 May 2017

Revised 7 August 2017 Accepted 24 August 2017

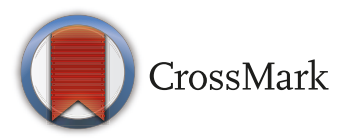

For numbered affiliations see end of article.

Correspondence to

Professor Yan Lin;

ylin@theunion.org

\section{ABSTRACT}

Objective The association between tuberculosis (TB), diabetes mellitus (DM) and vitamin D status is poorly characterised. We therefore: (1) determined vitamin D status in patients with TB in relation to whether they had normal fasting blood glucose (FBG), pre-DM or DM and (2) assessed whether baseline characteristics in patients with TB, including their DM status, were associated with vitamin $\mathrm{D}$ deficiency.

Methods In patients with TB consecutively attending six clinics or hospitals in China, we measured 25-hydroxycholecalciferol $\left(25-(\mathrm{OH}) \mathrm{D}_{3}\right)$ at the time of registration using electrochemiluminescence in a COBASE 601 Roche analyser by chemiluminescence immunoassay. Data analysis was performed using the $\chi^{2}$ test, ORs and multivariate logistic regression.

Results There were 306 eligible patients with TB, including 96 with smear positive pulmonary TB, 187 with smear negative pulmonary TB and 23 with extrapulmonary TB. Of these, 95 (31\%) had normal blood glucose, 83 (27\%) had pre-DM and $128(42 \%)$ had DM. Median serum vitamin D levels were $16.1 \mathrm{ng} / \mathrm{mL}$ in patients with TB with normal FBG, $12.6 \mathrm{ng} / \mathrm{mL}$ in patients with TB with pre-DM and $12.1 \mathrm{ng} / \mathrm{mL}$ in patients with TB with $\mathrm{DM}(\mathrm{p}<0.001)$. The study highlighted certain baseline characteristics associated with vitamin $D$ deficiency $\left(25-(\mathrm{OH}) \mathrm{D}_{3}<20 \mathrm{ng} /\right.$ $\mathrm{mL}$ ). After adjusting for confounders, serum vitamin $D$ deficiency was significantly more common in patients being registered in the cold season (November to April) $(p=0.006)$ and in those with DM $(p=0.003)$.

Conclusion Vitamin $D$ levels are lower in patients with TB with pre-DM and DM and are also affected by certain baseline characteristics that include being registered in the cold season and having DM. TB programmes need to pay more attention to vitamin $D$ status in their patients, especially if there is coexisting pre-DM or DM.

\section{INTRODUCTION}

Despite the $47 \%$ decline in tuberculosis (TB) mortality since 1990 , the disease remains a major global public health threat. In 2015, 10.4 million people developed active TB and 1.4 million people (without HIV infection)
Strengths and limitations of this study

- In contrast to many previous studies on this subject in China, the current study enrolled a large number of patients with tuberculosis (TB) who were consecutively registered in the routine programme setting in urban and rural settings.

- Rural settings were further divided into non-poverty and poverty areas to assess the influence of this factor on 25-hydroxycholecalciferol $\left(25-(\mathrm{OH}) \mathrm{D}_{3}\right)$ levels.

- Blood samples for measurement of $25-(\mathrm{OH}) \mathrm{D}_{3}$ were taken without collecting detailed information about the patient's history, and there is, therefore, no data on duration of symptoms or signs which might have impacted on vitamin D levels.

- The presence or absence of comorbidities that affect vitamin D status depended on medical documentation or patient self-reports and these may have been missed.

- 25- $(\mathrm{OH}) \mathrm{D}_{3}$ levels were only measured at one time before anti-TB treatment and therefore there is no information about whether these changed during the 6-month course of anti-TB treatment.

were estimated to have died from the disease. ${ }^{1}$ Successful treatment for TB depends on a standardised, supervised 6-month course of anti-TB drugs and also on nutritional wellbeing and support. ${ }^{12}$

Vitamin D is a secosteroid synthesised in the skin by the action of sunlight and also ingested in the diet. It has pleiotropic effects on many organs and plays a key role in human innate and adaptive immunity. ${ }^{34}$ In the context of TB, Vitamin D assists mononuclear phagocytes to suppress the intracellular growth of Mycobacterium tuberculosis after initial infection. ${ }^{56}$ Vitamin D does this by undergoing metabolic activation mainly in the liver to 25-hydroxycholecalciferol $\left(25-(\mathrm{OH}) \mathrm{D}_{3}\right)$ and then in the kidney to 
1,25-dihydroxycholecalciferol $\left(1,25-(\mathrm{OH})_{2} \mathrm{D}_{3}\right)$, the latter being an immunologically active hormone that stimulates antimycobacterial activity in vitro. ${ }^{34}$

Previous reports have shown that people with vitamin $\mathrm{D}$ deficiency have a significantly higher risk of developing active TB compared with those who have normal vitamin D levels. ${ }^{378}$ This has been particularly observed in migrants coming to the UK from Asia. ${ }^{9}$ Patients with TB have also generally been reported to have lower serum levels of vitamin D compared with normal controls. ${ }^{10}{ }^{11}$ These studies have suggested that vitamin D supplementation during anti-TB treatment in areas endemic for vitamin $\mathrm{D}$ deficiency, particularly in poor communities, might improve the response to anti-TB treatment. Conversely, however, other studies have shown no improved treatment response in terms of sputum culture conversion and final treatment outcomes between those receiving vitamin D supplementation and those without. ${ }^{91213}$ These conflicting reports beg the question as to whether vitamin D deficiency is equally distributed among patients with different types and categories of TB or among patients with TB with other coexisting comorbidities, such as diabetes mellitus (DM).

Persons with DM have three times the risk of developing active TB compared with normal people, for reasons that are not particularly well understood. ${ }^{14} 15$ Vitamin D deficiency may play a role in this association. ${ }^{316}$ Proteomic analysis has suggested that there are qualitative differences in the vitamin D-binding protein precursor and other proteins between patients with TB with and without DM. ${ }^{17}$ Findings from an intervention study have also shown that when monocyte-derived macrophages from patients with DM with low vitamin D receptor expression were supplemented with vitamin $\mathrm{D}$, the cellular function of eliminating M. tuberculosis improved. $^{18}$

Clinical studies have also been undertaken but have shown conflicting results. Chaudhary et al analysed vitamin D status, using a radioimmunoassay method, and reported no difference in serum vitamin D levels between patients with $\mathrm{TB}$ and patients with TB with DM, although the prevalence of severe vitamin D deficiency was highest in the group of patients with DM-TB. ${ }^{19}$ Conversely, a small-scale study in urban China, using liquid chromatography-tandem mass spectrometry, reported significant differences in vitamin D levels among patients with TB, TB with pre-DM and DM-TB.$^{10}$ There have been no reports of studies looking at associations between vitamin $\mathrm{D}, \mathrm{DM}$ and TB within routine programmatic settings. We therefore: (1) determined vitamin $\mathrm{D}$ status in patients with $\mathrm{TB}$ in relation to whether they had normal fasting blood glucose (FBG), pre-DM or DM and (2) assessed whether baseline characteristics in patients with TB with normal FBG, pre-DM and DM status were associated with vitamin $\mathrm{D}$ deficiency.
METHODS

\section{Design}

This was a cross-sectional study carried out at six TB clinics and hospitals within the routine health services in Jilin province, China. Total sample size was calculated using a simplified two-sided significance level of 0.05 and a power of 0.8 . We assumed, based on previous studies, that at least $10 \%-15 \%$ of patients with TB in China would have serum vitamin D deficiency. ${ }^{20}{ }^{21}$ Therefore, the minimum required sample size was 62-93. However, taking into account poor collection of serum samples in the field of $15 \%$ and another $20 \%$ of blood samples losing their quality during long-distance transportation, we needed to recruit at least 129 patients with TB. Previous experience with this type of work in China has indicated the need to add $5 \%$ onto the number of recruited patients due to missing key information variables and another $10 \%$ to include different types of TB. Our sample size was therefore at least 148 patients with TB.

\section{Setting and sites}

Previous reports suggested that the prevalence of vitamin $\mathrm{D}$ deficiency varies depending on the economic situation of study subjects' residential areas. ${ }^{6}$ Therefore, we selected two TB hospitals in urban areas (Liaoyuan City Chest Hospital and Tonghua City TB Hospital), three TB clinics in non-poverty rural areas (Dongfeng County TB Institute, Meihekou City TB Institute and Tonghua County TB Institute) and one TB clinic in a poverty rural area (Daan County TB Institute), a State poverty county streamlined by China State Council with an average annual farmers' income of less than US\$189. The selection of the clinics and hospitals was based on broad economic development levels, a sufficient number of patients with TB stratified by different types of the disease, the availability of blood sample storage facilities and the willingness of the staff to participate in the study without incentives.

\section{Patient recruitment}

Patients who were consecutively diagnosed and registered with TB from November 2015 to July 2016 were included in the study. The diagnosis of TB was made in line with recommendations from $\mathrm{WHO}$ and the China National TB Program guidelines. ${ }^{22}{ }^{23}$ Patients with suspected TB were investigated by sputum smear microscopy. If sputum specimens were smear positive for acid-fast bacilli, the patient was diagnosed as smear positive pulmonary TB. If sputum smears were negative, but the patient had TB-related symptoms and chest radiography that was compatible with active pulmonary $\mathrm{TB}$, the patient was diagnosed as smear negative pulmonary $\mathrm{TB}$ after a formal consultation by physicians. Extrapulmonary TB (EPTB) was diagnosed on clinical grounds, using additional circumstantial evidence such as radiography, ultrasound and laboratory investigations according to the site of the lesion: for a diagnosis of EPTB to be made there had to be at least one specimen with confirmed M. tuberculosis on smear/ culture or histological evidence of TB or strong clinical 
and circumstantial evidence consistent with the presence of active extrapulmonary disease.

The patients included were $\geq 18$ years and newly registered with any type and category of TB according to the national and international guidelines. ${ }^{22}{ }^{23}$ Exclusion criteria included: (1) pregnant or lactating women, (2) being positive for HIV, (3) having aspartate aminotransferase or alanine aminotransferase $\geq 3$ times the upper limit of normal level as hepatic dysfunction may alter vitamin D metabolism, (4) receiving vitamin D or vitamin D analogues for any reason, (5) receiving corticosteroid treatment for any reason and (6) having cancer or receiving anticancer therapy.

\section{Blood sample collection}

After the patients were registered, $5 \mathrm{~mL}$ venous blood sample was taken immediately following an overnight fast of at least 10 hours. The samples were centrifuged within 2 hours to separate the serum and stored at $-20^{\circ} \mathrm{C}$. All serum samples were transported to the local Centres for Disease Control or blood bank within 7 days and stored at $-70^{\circ} \mathrm{C}$ until analysis was undertaken in two single batches.

\section{Vitamin D measurement and definition}

The major circulating metabolite of vitamin $\mathrm{D}$ is 25-hydroxycholecalciferol $\quad\left(25-(\mathrm{OH}) \mathrm{D}_{3}\right)$, which was measured in the Laboratory Medicine Department of Beijing Hospital using the electrochemiluminescence method that determines serum $25-(\mathrm{OH}) \mathrm{D}_{3}$ levels in a COBASE 601 Roche analyser using a chemiluminescence immunoassay. Reagents were supplied from Roche with a normal measurement range of $3-70 \mathrm{ng} / \mathrm{mL}$. In brief, the assay uses a polyclonal antibody directed against $25-(\mathrm{OH}) \mathrm{D}_{3}$. Two incubations are required with the specified reagents, following which the reaction mixture is aspirated into a measuring cell where application of a voltage to the electrode then induces a chemiluminescent emission which is measured by a photomultiplier. Results are determined via a calibration curve. ${ }^{24}$ Holick's definitions of vitamin D status were used: $25-(\mathrm{OH}) \mathrm{D}_{3} \geq 30 \mathrm{ng} /$ $\mathrm{mL}=$ normal; $25-(\mathrm{OH}) \mathrm{D}_{3}$ between 20 and $29.9 \mathrm{ng} / \mathrm{mL}=\mathrm{in}-$ sufficient vitamin $\mathrm{D} ; 25-(\mathrm{OH}) \mathrm{D}_{3}$ between 10 and $19.9 \mathrm{ng} /$ $\mathrm{mL}=$ vitamin $\quad \mathrm{D}$ deficiency; $25-(\mathrm{OH}) \mathrm{D}_{3}$ between 0 and $9.9 \mathrm{ng} / \mathrm{mL}=$ severe vitamin $\mathrm{D}$ deficiency.

\section{Data collection and recording}

A standardised questionnaire was developed for data collection focusing on demographic characteristics, types and categories of TB, symptoms, complications and cigarette smoking status. Patients were diagnosed with DM either as a result of this being already known (DM diagnosed at any time by a registered medical institution and documented in the clinic notes) or as a result of FBG $\geq 7.0 \mathrm{mmol} / \mathrm{L}$ being identified at the time of TB registration or at the time of TB diagnosis from another health facility. Pre-DM was identified as a result of FBG $6.1-6.9 \mathrm{mmol} / \mathrm{L}$ at the time of $\mathrm{TB}$ registration based on WHO definition. ${ }^{25}$ The questionnaire was compiled by
TB clinic staff and reviewed by the provincial and Union staff during monitoring visits and before data entry and analysis.

\section{Data analysis and statistics}

Individual patient data were entered to an EXCEL file by the principal investigator. Non-parametric tests (Kruskal-Wallis $\mathrm{H}$ ) were used to compare median levels of vitamin D $\left(25-(\mathrm{OH}) \mathrm{D}_{3}\right)$ between groups. Comparisons of characteristics of patients with TB between those with normal FBG, pre-DM and DM and categorical comparisons of various 25- $(\mathrm{OH}) \mathrm{D}_{3}$ levels between patients with $\mathrm{DM}$, pre-DM and normal FBG were carried out using the $\mathrm{X}^{2}$ test. Relationships between $25-(\mathrm{OH}) \mathrm{D}_{3}$ and associated exposure variables were evaluated with ORs and 95\% CIs. We selected variables with unadjusted ORs for which the $\mathrm{p}$ value was $<0.05$ and included these in a multivariate logistic regression model using SPSS V.13.0 (SPSS). Levels of significance were set at $5 \%$.

\section{Ethics approval}

The research proposal was reviewed and approved by the provincial authorities in the implementing sites. The Ethics Advisory Group, International Union Against Tuberculosis and Lung Disease, Paris, France, formally approved this study (EAG number: 102/15). A written informed consent was obtained from participants.

\section{RESULTS}

There were 317 patients with TB consecutively registered in this study. Of these, 11 were excluded because of insufficient volumes of serum or absence of key information variables. Of 306 eligible patients with TB, 96 had smear-positive pulmonary TB, 187 had smear-negative pulmonary TB and 23 had EPTB. There were 215 men and 91 women, aged from 18 to 92 years with a mean of 51.5 years. Of 306 patients with TB, 95 had normal FBG, 83 had pre-DM and 128 had DM. The group of patients with TB with normal FBG was younger $(\mathrm{p}<0.001)$, had a higher proportion with rural citizenship $(\mathrm{p}=0.026)$, a lower proportion with retreatment TB $(\mathrm{p}=0.016)$ and a higher proportion registered in the months of May to October (the warm season) compared with the DM-TB group: there no other statistically significant differences between the groups (table 1 ).

Serum vitamin $\mathrm{D}\left(25-(\mathrm{OH}) \mathrm{D}_{3}\right)$ levels in patients with TB with normal FBG were higher than those found in patients with pre-DM-TB and patients with DM-TB (table 2). The proportions of patients with vitamin $\mathrm{D}$ deficiency or severe vitamin D deficiency were $61.1 \%$ for those with TB and normal FBG, $74.7 \%$ for those with pre-DM and $83.6 \%$ for those with DM $(p<0.001)$ The median serum vitamin D levels and their distributions in general were similar between Daan county (the rural poverty county) and the other sites ( $p>0.05)$, although there was a higher proportion of patients with normal 
Table 1 Characteristics of the 306 recruited patients with TB

\begin{tabular}{|c|c|c|c|c|c|}
\hline \multirow[b]{3}{*}{ Characteristics } & \multicolumn{3}{|c|}{ No $(\%)$ of patients with TB } & \multirow[b]{3}{*}{$\chi^{2}$} & \multirow[b]{3}{*}{ p Value } \\
\hline & Normal FBG & Pre-DM & DM & & \\
\hline & $(n=95)$ & $(n=83)$ & $(n=128)$ & & \\
\hline \multicolumn{6}{|l|}{ Sex } \\
\hline Male & 69 (72.6) & $57(68.7)$ & 89 (69.5) & 0.38 & 0.82 \\
\hline Female & $26(27.4)$ & $26(31.3)$ & $39(30.5)$ & & \\
\hline \multicolumn{6}{|l|}{ Age } \\
\hline$<40$ & $32(33.7)$ & $20(24.1)$ & $13(10.2)$ & 21.4 & $<0.001$ \\
\hline $40-59$ & $42(44.2)$ & $34(41.0)$ & $62(48.4)$ & & \\
\hline$\geq 60$ & $21(22.1)$ & 29 (34.9) & $53(41.4)$ & & \\
\hline \multicolumn{6}{|l|}{ Residence } \\
\hline Urban & $25(26.3)$ & 24 (28.9) & 54 (42.2) & 7.3 & 0.03 \\
\hline Rural & $70(73.7)$ & $59(71.1)$ & $74(57.8)$ & & \\
\hline \multicolumn{6}{|l|}{ Type/sputum smear } \\
\hline Positive & $33(34.7)$ & $26(31.3)$ & $37(28.9)$ & 2.8 & 0.6 \\
\hline Negative & $56(58.9)$ & $48(57.8)$ & $83(64.8)$ & & \\
\hline EPTB & $6(6.4)$ & 9 (10.9) & $8(6.3)$ & & \\
\hline \multicolumn{6}{|l|}{ Category of TB } \\
\hline New & $84(88.4)$ & $64(77.1)$ & $93(72.7)$ & 8.29 & 0.02 \\
\hline Retreatment & $11(11.6)$ & 19 (22.9) & $35(27.3)$ & & \\
\hline \multicolumn{6}{|c|}{ Smoking cigarette/day } \\
\hline 0 & $44(46.3)$ & $32(38.6)$ & $59(46.1)$ & 10.4 & 0.11 \\
\hline $1-9$ & $12(12.6)$ & $19(22.9)$ & $27(21.1)$ & & \\
\hline $10-19$ & $22(23.2)$ & $25(30.1)$ & $32(25.0)$ & & \\
\hline$\geq 20$ & $17(17.9)$ & 7 (8.4) & $10(7.8)$ & & \\
\hline \multicolumn{6}{|c|}{ Month of TB registration } \\
\hline May-October & $44(46.3)$ & $34(41.0)$ & $39(30.5)$ & 6.16 & 0.046 \\
\hline November-April & $51(53.7)$ & 49 (59.0) & $89(69.5)$ & & \\
\hline \multicolumn{6}{|l|}{ Poverty area } \\
\hline Yes & $18(18.9)$ & $14(16.9)$ & 25 (19.5) & 0.25 & 0.89 \\
\hline No & 77 (81.1) & 69 (83.1) & $103(80.5)$ & & \\
\hline
\end{tabular}

May-October=the warm months of the year; November-April=the cold months of the year.

DM, diabetes mellitus; EPTB, extrapulmonary tuberculosis; FBG, fasting blood glucose; Pre-DM, prediabetes mellitus; TB, tuberculosis.

Table 2 Vitamin D status in patients with TB in China, stratified by those with normal FBG, pre-DM and DM

\begin{tabular}{llllc}
\hline & $\begin{array}{l}\text { Patients with TB with } \\
\text { normal FBG, } \\
\mathbf{n = 9 5}\end{array}$ & $\begin{array}{l}\text { Patients with TB } \\
\text { with pre-DM, } \\
\mathbf{n = 8 3}\end{array}$ & $\begin{array}{l}\text { Patients with TB } \\
\text { with DM, } \\
\mathbf{n = 1 2 8}\end{array}$ & p Value \\
\hline Median level $(\mathrm{ng} / \mathrm{mL})$ & 16.1 & 12.6 & 12.1 & $<0.01$ \\
\hline No $(\%)$ with normal level $(\geq 30 \mathrm{ng} / \mathrm{mL})$ & $23(24.2)$ & $8(9.6)$ & $3(2.3)$ & $<0.001$ \\
\hline No $(\%)$ with insufficiency $(20-29.9 \mathrm{ng} / \mathrm{mL})$ & $14(14.7)$ & $13(15.7)$ & $18(14.1)$ & 0.63 \\
\hline No $(\%)$ with deficiency $(10-19.9 \mathrm{ng} / \mathrm{mL})$ & $39(41.1)$ & $34(41.0)$ & $69(53.9)$ & $<0.01$ \\
\hline No $(\%)$ with severe deficiency $(\leq 9.9 \mathrm{ng} / \mathrm{mL})$ & $19(20.0)$ & $28(33.7)$ & $38(29.7)$ & 0.041 \\
\hline
\end{tabular}

Vitamin $\mathrm{D}$ status determined by measurements of $25-(\mathrm{OH}) \mathrm{D}_{3}$.

25- $(\mathrm{OH}) \mathrm{D}_{3}$, 25-hydroxycholecalciferol; DM, diabetes mellitus; FBG, fasting blood glucose; pre-DM, prediabetes diabetes mellitus; TB,

tuberculosis. 


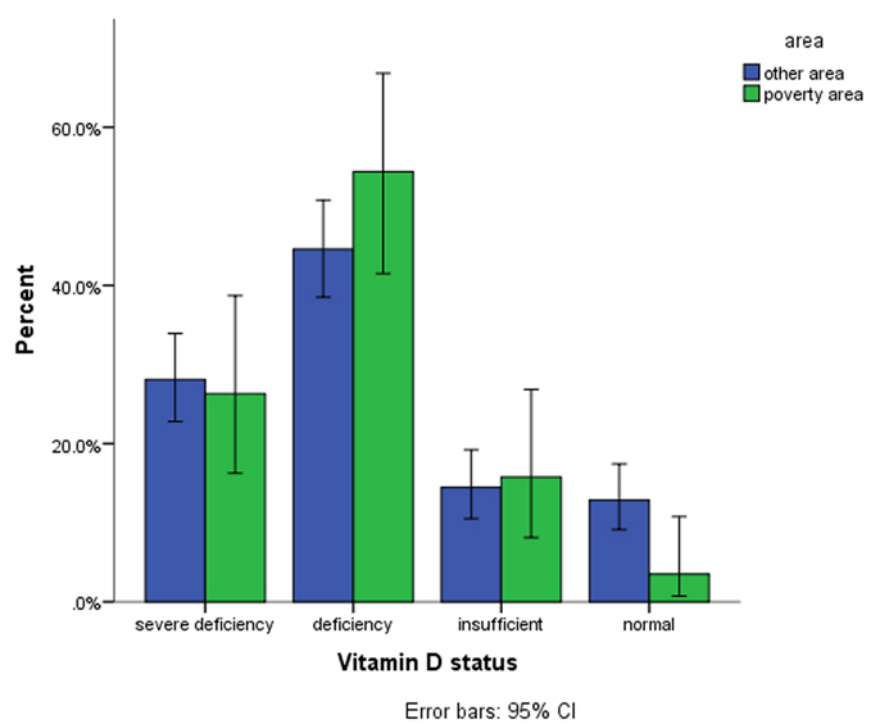

Figure 1 Vitamin D status of patients with tuberculosis in the poverty rural area compared with other non-poverty areas in China.

vitamin D levels residing in areas classified as non-poverty $(p=0.032)$ (figure 1).

Baseline characteristics of patients with $\mathrm{TB}$, including those with normal FBG, pre-DM and DM in relation to having vitamin $\mathrm{D}$ deficiency/severe deficiency are shown in table 3. After adjusting for confounders with logistic regression, the main characteristics associated with having a higher risk of vitamin $\mathrm{D}$ deficiency were the month of TB registration (November to April-the cold months) and having DM.

\section{DISCUSSION}

Our study presents findings of vitamin D status among different types of patients with TB and in relation to their DM status.

First, the median level of vitamin $\mathrm{D}$ in patients with TB with normal FBG at $16.1 \mathrm{ng} / \mathrm{mL}$ was lower than that found in the general population $(26.3 \mathrm{ng} / \mathrm{mL}),{ }^{26}$ and this finding is similar to that reported from other studies. 61020 Once anti-TB treatment is initiated, serum vitamin D levels may be further depressed through the action of drugs such as rifampicin which increase liver metabolism, ${ }^{27}$ and TB clinic staff need to be made aware of this fact.

Second, serum vitamin D levels in patients with TB with pre-DM and with DM were significantly lower than in patients with TB with normal FBG, with a similar trend having also been found in a small-scale study in urban settings of China. ${ }^{10}$ This was mirrored by the higher proportions of patients with pre-DM and DM with vitamin D deficiency and severe deficiency compared with patients with $\mathrm{TB}$ who had normal glucose levels. However, these are not consistent observations with a report in India finding no significant differences in mean vitamin D levels between groups with TB, DM or a combination of both. ${ }^{19}$ Both TB and DM can be associated with suboptimal nutritional intake, but in this observational cross-sectional study we were unable to attribute any causal association as to whether low vitamin D status increases the risk of $\mathrm{TB}$ or $\mathrm{DM}$ or whether $\mathrm{DM}$ or TB increases the risk of vitamin $\mathrm{D}$ deficiency.

Third, of the six sites participating in this study, one was located in an area characterised as a State Poverty County streamlined by China State Council. Here, there was a significantly lower proportion of patients with TB with normal vitamin $\mathrm{D}$ status, although the general distribution of vitamin D status from normal to severe deficiency was no different compared with the other sites. It is unclear then whether there is any need for interventions focused on improving nutritional intake or fortifying food with vitamin D supplements in this particular area and this needs further discussion.

Fourth, our study highlighted certain characteristics associated with vitamin D deficiency in patients with TB. Patients with TB registered in the colder months of the year (November to April) had a higher risk of vitamin D deficiency compared with those registered in the warmer months (May to October). This is similar to findings observed in Malawi, ${ }^{12}$ and is possibly due to less sunlight and more time spent indoors during winter months. ${ }^{28}$ The study sites were also situated in the north-east of China with where the winter season is long and very cold winter season. The prices of vegetable, fruit and other food are far more expensive than those in the summer time, and this may lead to reduced nutritional intake, particularly for poor people.

Reports from Vietnam and Afghanistan have found gender differences in vitamin $\mathrm{D}$ status to be important for patients with $\mathrm{TB}^{29}{ }^{30}$ but this was not observed in our study, and this may be due to a relatively higher general nutritional status for both men and women in the Chinese population. $^{31}$

Our study also found that DM was an independent risk factor for vitamin D deficiency after adjusting for other baseline characteristics. A recent study in China found that older age, a family history of DM and being overweight or underweight were associated with pre-DM and $\mathrm{TB}$, with pre-DM itself being a risk factor for the development of DM. ${ }^{32}$ Both DM and TB are associated with impaired nutritional intake and this might result in low levels of 25- $(\mathrm{OH}) \mathrm{D}_{3} \cdot{ }^{33}$ Among our study subjects, the age of patients with TB with DM was generally older than that of patients with TB with normal FBG. A previous study in China showed that elderly patients with TB experienced long delays in accessing health services and this might also contribute to poor vitamin D status. ${ }^{34}$

The strengths of our study were the large number of patients with TB enrolled and the consecutive registration process to prevent selection bias. There were, however, some limitations. We took blood samples for measurement of $25-(\mathrm{OH}) \mathrm{D}_{3}$ immediately after the diagnosis of TB without collecting the patient's history. We therefore do not know the duration of symptoms or signs of $\mathrm{TB}$, a factor which might have impacted on serum 
Table 3 Characteristics of patients with TB in China in relation to vitamin D deficiency and severe deficiency $(<20 \mathrm{ng} / \mathrm{mL})$

\begin{tabular}{|c|c|c|c|c|c|}
\hline Characteristics & $\begin{array}{l}\text { Total } \\
\mathrm{n}=306\end{array}$ & $\begin{array}{l}\text { No (\%) with vitamin D } \\
\text { deficiency }\end{array}$ & $\begin{array}{l}\text { Univariate OR } \\
(95 \% \mathrm{Cl})\end{array}$ & $\begin{array}{l}\text { Multivariate adjusted OR } \\
(95 \% \mathrm{Cl})\end{array}$ & p Value \\
\hline Female & 91 & $65(71.4)$ & Reference & & \\
\hline Male & 215 & $162(75.3)$ & 1.22 (0.71 to 2.12 ) & & \\
\hline \multicolumn{6}{|l|}{ Age } \\
\hline$<40$ & 65 & $41(63.1)$ & Reference & Reference & \\
\hline $40-59$ & 138 & $103(74.6)$ & 1.72 (0.92 to 3.24$)$ & 1.30 (0.67 to 2.54$)$ & 0.438 \\
\hline$\geq 60$ & 103 & $83(80.6)$ & 2.43 (1.21 to 4.90$)$ & 1.58 (0.75 to 3.34$)$ & 0.230 \\
\hline \multicolumn{6}{|l|}{ Residence } \\
\hline Urban & 103 & $75(72.8)$ & Reference & & \\
\hline Rural & 203 & $152(74.9)$ & 1.11 (0.65 to 1.91$)$ & & \\
\hline \multicolumn{6}{|l|}{ Type/sputum smear } \\
\hline Positive & 96 & $66(68.8)$ & Reference & & \\
\hline Negative & 187 & $144(77.0)$ & 1.52 (0.88 to 2.64$)$ & & \\
\hline EPTB & 23 & 17 (73.9) & 1.29 (0.46 to 3.59$)$ & & \\
\hline \multicolumn{6}{|l|}{ Category of TB } \\
\hline New & 241 & $175(72.6)$ & Reference & & \\
\hline Retreatment & 65 & $52(80.0)$ & 1.51 (0.77 to 2.95$)$ & & \\
\hline \multicolumn{6}{|c|}{ Smoking cigarette/day } \\
\hline 0 & 135 & $92(68.1)$ & Reference & & \\
\hline $1-9$ & 58 & $46(79.3)$ & 1.79 (0.86 to 3.72$)$ & & \\
\hline $10-19$ & 79 & $60(75.9)$ & 1.48 (0.79 to 2.77 ) & & \\
\hline$\geq 20$ & 34 & 29 (85.3) & 2.71 (0.98 to 7.49$)$ & & \\
\hline \multicolumn{6}{|c|}{ Month of TB registration } \\
\hline May-October & 117 & $74(63.2)$ & Reference & Reference & \\
\hline November-April & 189 & $153(81.0)$ & 2.47 (1.46 to 4.17 ) & 2.15 (1.25 to 3.69$)$ & 0.006 \\
\hline \multicolumn{6}{|l|}{ FBG level } \\
\hline Normal & 95 & $58(61.1)$ & Reference & Reference & \\
\hline Pre-DM & 83 & $62(74.7)$ & 1.88 (0.99 to 3.59 ) & 1.77 (0.91 to 3.43 ) & 0.090 \\
\hline DM & 128 & $107(83.6)$ & 3.25 (1.74 to 6.06$)$ & $2.68(1.40$ to 5.15$)$ & 0.003 \\
\hline
\end{tabular}

$p$ Value is shown for the multivariate adjusted OR.

May-October=the warm months of the year; November-April=the cold months of the year.

Hosmer-Lemeshow good of fit: $\chi^{2}=7.910, p=0.341$, indicating the good of fit of logistic regression models is good.

DM, diabetes mellitus; EPTB, extrapulmonary tuberculosis; FBG, fasting blood glucose; Pre-DM, prediabetes diabetes mellitus; TB, tuberculosis.

vitamin $\mathrm{D}$ levels. The presence or absence of comorbidities depended on medical documentation or patient self-reports, so we may have overlooked some conditions impacting on vitamin $\mathrm{D}$ status because we did not actively screen for them. In addition, we only measured 25- $(\mathrm{OH})$ $\mathrm{D}_{3}$ levels at one time before anti-TB treatment and therefore do not know whether these levels changed during the 6-month course of anti-TB treatment.

\section{CONCLUSION}

Serum vitamin D levels were lower in patients with TB with pre-DM and DM compared with those whose FBG is normal. Vitamin D levels are also affected by certain baseline characteristics, with vitamin $\mathrm{D}$ deficiency being significantly higher in those with DM and those registered in the colder months of the year. TB Programmes need to pay more attention to vitamin D status in their patients, particularly during the cold season and if there is coexisting DM or pre-DM.

\section{Author affiliations}

${ }^{1}$ Department of Laboratory Medicine, Beijing Hospital, National Center of Gerontology, Beijing, Beijing, China

${ }^{2}$ Director Office, Jilin Provincial Academy of Tuberculosis Control and Prevention, Changchun, Jilin, China

${ }^{3}$ Department of TB and HIV, International Union Against Tuberculosis and Lung Disease, Paris, Paris, France 
${ }^{4}$ The Union China Office, International Union Against Tuberculosis and Lung Disease, Beijing, Beijing, China

${ }^{5}$ Department of Epidemiology, Beijing Chest Hospital, Capital Medical University,

Beijing, Beijing, China

${ }^{6}$ Department of Epidemiology, Beijing Tuberculosis and Thoracic Tumor Research Institute, Beijing, Beijing, China

${ }^{7}$ Department of Tuberculosis, Meihekou City Tuberculosis Institute, Meihekou, Jilin, China

${ }^{8}$ Department of Tuberculosis, Dongfeng County Tuberculosis Institute, Dongfeng, Jilin, China

${ }^{9}$ Department of TB and HIV, International Union Against Tuberculosis and Lung Diseases, Bulawayo, Bulawayo, Zimbabwe

${ }^{10}$ Department of Clinical Research, London School of Hygiene and Tropical Medicine, London, London, UK

Acknowledgements We thank all the staff at the six TB clinics and hospitals for their support in the blood sample collection, storage and managing patients.

Contributors $X Z, Y L$ and YY proposed the research idea. ADH, RAD and YL contributed to the study design. XZ worked on laboratory analysis and quality assurance. WK and YL conducted data entry and statistics analysis. TZ, JM, YB, YW and HS contributed to patient management, recording, reporting and blood sample transportation. YL, ADH and RAD contributed to the writing of the first draft. All authors contributed to the subsequent revisions of the paper. All authors read and approved the final paper for submission.Yan Lin,Yanli Yuan and Xin Zhao share the primary authorship.

Funding The authors bore their own costs for conducting this study and hence no specific funding line for this study.

Competing interests None declared.

Patient consent Obtained.

Ethics approval The Ethics Advisory Group, International Union Against Tuberculosis and Lung Disease, Paris, France.

Provenance and peer review Not commissioned; externally peer reviewed.

Data sharing statement The data are part of an ongoing study and are not available at this time.

Open Access This is an Open Access article distributed in accordance with the Creative Commons Attribution Non Commercial (CC BY-NC 4.0) license, which permits others to distribute, remix, adapt, build upon this work non-commercially, and license their derivative works on different terms, provided the original work is properly cited and the use is non-commercial. See: http://creativecommons.org/ licenses/by-nc/4.0/

(c) Article author(s) (or their employer(s) unless otherwise stated in the text of the article) 2017. All rights reserved. No commercial use is permitted unless otherwise expressly granted.

\section{REFERENCES}

1. World Health Organization. WHO Report 2016.Global Tuberculosis Control. 2015. available at www.who.int/tb/publication/global_report/ en.

2. Frieden T. Toman's Tuberculosis. Geneva: World Health Organization, 2004. Second Edition.

3. Zittermann A. Vitamin D in preventive medicine: are we ignoring the evidence? Br J Nutr 2003;89:552-72.

4. Holick MF, Chen TC. Vitamin D deficiency: a worldwide problem with health consequences. Am J Clin Nutr 2008;87:1080-s-1086s.

5. Chesdachai $S$, Zughaier SM, Hao L, et al. The effects of firstline anti-tuberculosis drugs on the actions of vitamin $D$ in human macrophages. J Clin Transl Endocrinol 2016;6:23-9.

6. Sutaria N, Liu CT, Chen TC, et al. Vitamin D Status, Receptor Gene Polymorphisms, and supplementation on tuberculosis: A systematic review of case-Control studies and randomized controlled trials. $J$ Clin Transl Endocrinol 2014:1:151-60.

7. Zeng J, Wu G, Yang W, et al. A serum vitamin D level. Plos One 2015

8. Arnedo-Pena A, Juan-Cerdán JV, Romeu-García A, et al. Vitamin D status and incidence of tuberculosis among contacts of pulmonary tuberculosis patients. Int J Tuberc Lung Dis 2015;19:65-9.
9. Davies PD, Martineau AR. Vitamin D and tuberculosis: more effective in prevention than treatment? Int J Tuberc Lung Dis 2015;19:876-7.

10. Zhan Y, Jiang L. Status of vitamin D, antimicrobial peptide cathelicidin and T helper-associated cytokines in patients with diabetes mellitus and pulmonary tuberculosis. Exp Ther Med 2015;9:11-16.

11. Wang Q, Ma A, Bygbjerg IC, et al. Rationale and design of a randomized controlled trial of the effect of retinol and vitamin $D$ supplementation on treatment in active pulmonary tuberculosis patients with diabetes. BMC Infect Dis 2013;13:104-21 http://www. biomedcentral.com/1471-2334/13/104.

12. Sloan DJ, Mwandumba HC, Kamdolozi M, et al. Vitamin D deficiency in Malawian adults with pulmonary tuberculosis: risk factors and treatment outcomes. Int $J$ Tuberc Lung Dis 2015;19:904-11.

13. Xia J, Shi L, Zhao L, et al. Impact of vitamin D supplementation on the outcome of tuberculosis treatment: a systematic review and meta-analysis of randomized control trials. Chinese medical $J$ 2014;127:3127-34.

14. Stevenson CR, Critchley JA, Forouhi NG, et al. Diabetes and the risk of tuberculosis: a neglected threat to public health? Chronic IIIn 2007;3:228-45.

15. Jeon CY, Murray MB. Diabetes mellitus increases the risk of active tuberculosis: a systematic review of 13 observational studies. PLoS Med 2008;5:e152.

16. Mathieu C, Gysemans C, Giulietti A, et al. Vitamin D and diabetes. Diabetologia 2005;48:1247-57.

17. Zhang X, Ma A, Sun S, et al. Proteomic analysis of plasma in adult active pulmonary tuberculosis patients with diabetes mellitus. Clin Lab 2015;61:1481-90.

18. Lopez-Lopez N, Gonzalez-Curiel I, Castañeda-Delgado J, et al. Vitamin D supplementation promotes macrophages' antimycobacterial activity in type 2 diabetes mellitus patients with low vitamin D receptor expression. Microbes Infect 2014;16:755-61.

19. Chaudhary S, Thukral A, Tiwari S, et al. Vitamin D status of patients with type 2 diabetes and sputum positive pulmonary tuberculosis. Indian J Endocrinol Metab 2013;17(Suppl 3):670-3.

20. Zhu H, Cheng Q, Gan J, et al. Vitamin D status in healthy man and woman in Shanghai. Chinese J Oste \& Bon Min 2010;3:157-63.

21. Wang S, Shen G, Jiang S, et al. Nutrient Status of Vitamin D among Chinese Children. Nutrients 2017;9:319.

22. Ministry of Health and China CDC. Guideline of national TB control program. Beijing: The Peking Union Medical College Publishing House, 2008.

23. World Health Organization. Treatment of Tuberculosis Guidelines. Fourth Edition. Geneva,Switzerland: WHO, 2009. WHO/HTM/ $\mathrm{TB} / 2009.420$

24. Roche. Vitamin D3 (25;OH);Cobas operational menu. V2 English, Roche, 2007-08, Switzerland.

25. World Health Organization and International Diabetes Federation. Definition and Diagnosis of Diabetes Mellitus and Intermediate Hyperglycaemia. Geneva, Switzerland: WHO, 2006. www.who.int/ diabetes/publications/diagnosis_diabetes2006/en/.

26. Wei QS, Chen ZQ, Tan X, et al. Relation of age, sex and bone minera density to Serum 25-Hydroxyvitamin D levels in Chinese women and Men. Orthop Surg 2015;7:343-9.

27. Bikle DD. What is new in vitamin D: 2006-2007. Curr Opin Rheumatol 2007;19:383-8.

28. Sedrani SH, Elidrissy AW, El Arabi KM. Sunlight and vitamin D status in normal Saudi subjects. Am J Clin Nutr 1983;38:129-32.

29. Sarin P, Duffy J, Mughal Z, et al. Vitamin D and tuberculosis: review and association in three rural provinces of Afghanistan. Int J Tuberc Lung Dis 2016;20:383-8.

30. Ho-Pham LT, Nguyen ND, Nguyen TT, et al. Association between vitamin $D$ insufficiency and tuberculosis in a Vietnamese population. BMC Infect Dis 2010;10:306-10.

31. World Health Organization. WHO Report 2016 World Health Statistics2016. . www.who.int/gho/publications/world_health_ statistics/en

32. Wang $Q$, Ma $A$, Han $X$, et al. Prevalence of type 2 diabetes among newly detected pulmonary tuberculosis patients in China: a community based cohort study. PLoS One 2013;8:e82660.

33. Wang $Q$, Ma A, Han X, et al. Is low serum 25-hydroxyvitamin D a possible link between pulmonary tuberculosis and type 2 diabetes? Asia Pac J Clin Nutr 2017;26:241-6.

34. Lin Y, Enarson DA, Chiang CY, et al. Patient delay in the diagnosis and treatment of tuberculosis in China: findings of case detection projects. Public Health Action 2015;5:65-9. 